\title{
Limites e possibilidades de interlocução entre o dialogismo bakhtiniano e a psicanálise*1
}

\section{Limits and possibilities of an interlocution between Bakhtianian dialogism and psychoanalysis}

\author{
Marina Assis Pinheiro*2 \\ Mariana Bentzen Aguiar*3 \\ Glória Maria Monteiro de Carvalho*4
}

O presente artigo buscou - à luz do exercício de perscrutação de noções como singularidade, linguagem e alteridade - problematizar sobre a possibilidade de estabelecer "jogos de linguagem" e "semelhanças de familia" entre os pressupostos bakhtinianos e lacanianos, bem como marcar as suas diferenças. Esta tentativa alicerça-se no reconhecimento de um princípio dialógico na psicanálise, desde sua teorização sobre a constituição do sujeito. Por outro lado, a leitura dos textos bakhtinianos, inspirado pela psicanálise, também perspectiva novos versionamentos da noção de consciência, para além da gramática do sujeito do controle e do racionalismo. Propõe-se que, se por um lado é problemático indicar uma "confluência" entre Bakhtin e Lacan, por outro, são as diferenças que podem iluminar e gerar novas metáforas entre as duas abordagens discutidas.

Palavras-chave: Bakhtin, Lacan, singularidade, linguagem, alteridade

${ }^{* 1}$ Artigo inspirado pela tese de doutorado da primeira autora, de título: Singularidade e corpo: uma questão para a psicanálise, defendida em fevereiro de 2011 no Programa de Pós-Graduação em Psicologia Cognitiva da Universidade Federal de Pernambuco (Recife, PE, Br).

*2, ${ }^{3}$ Universidade Federal de Pernambuco UFPE (Recife, PE, Br).

${ }^{* 4}$ Universidade Católica de Pernambuco - Unicap (Recife, PE, Br). 


\section{ARTIGOS}

O sentido de convocar, ao mesmo plano de discussão, pressupostos bakhtinianos e psicanalíticos ocorre uma vez que esses dois contextos discursivos parecem compartilhar - por caminhos bastante diversos uma preocupação ímpar sobre a singularidade, linguagem e alteridade nos processos de subjetivação e de estetização da existência.

$\mathrm{O}$ intento de provocar algum diálogo entre essas duas abordagens é tarefa bastante arriscada, tendo em vista as duras críticas a Freud que encontramos em Bakhtin (ver Bakhtin, 2007). Sem dúvida, as duas perspectivas se diferenciam, sobretudo na concepção de linguagem, singularidade e de sujeito, tornando, aparentemente, inviáveis quaisquer aproximações. De uma parte teríamos o sujeito das pulsões, do inconsciente regido sobre a ordem significante da linguagem. Já em Bakhtin, encontraríamos uma concepção de subjetividade em que o sentido linguístico, as vozes performatizantes da consciência e o contexto pragmático das enunciações, formam um importante núcleo de reflexões sobre a ação criativa. Tratar-se-ia de universos muito diversos um do outro, configurando portanto, no vocabulário da filosofia, teses incomensuráveis, ou seja, da radical diferença por suas especificidades discursivas, propósitos éticos e metodológicos.

Entretanto, à luz do exercício de perscrutação de conceitos como singularidade, linguagem e alteridade, é proposta do presente artigo a possibilidade de estabelecermos aqui algumas "semelhanças de família" - no sentido wittgensteiniano (1999) do termo - entre as referidas abordagens acerca da condição humana. Essa noção, utilizada aqui apenas como recurso instrumental à produção do debate, chama a atenção para a impossibilidade da correspondência ou de "algo comum" entre as linguagens. Propõe-se, então, que seria impossível traduzir uma teoria pela linguagem de outra. $\mathrm{O}$ ponto de encontro comum seria pensado como uma ilusão platônica. Tudo o que poderíamos apontar seria para semelhanças: como a de membros de uma família que guardam certos traços em comum, mas que permanecem como seres distintos, cujas possíveis similaridades não dizem nada além de semelhanças aparentes, vizinhanças, e não uma essência ou fixação de sentidos equivalentes nos enunciados. 
Esse exercício de espelhamento diferenciador entre as duas perspectivas postas em discussão é pouco exercitado na literatura acadêmica. Buscando os termos-chave "Bakhtin", "Lacan", "psicanálise", "lacaniano", "bahktiniano" e "psicanalítico", em língua portuguesa e inglesa, nos títulos e resumos de produções acadêmicas somente obtivemos seis resultados: dois artigos nos Periódicos Capes (Novaes \& Rudge, 2007; Moura-Vieira, 2009), um artigo no US National Library of Medicine National Institutes of Health (PubMed) (Gerofsky, 2010), um artigo (Baker, 1995), uma tese (Luo, 2015) e um livro no Google Acadêmico (Ascroft, 2016).

Os resultados supracitados tornam-se ainda mais exíguos quando circunscrevermos a busca na literatura por diálogos referentes aos conceitos aqui propostos (singularidade, alteridade e linguagem); somente um artigo (Novaes \& Rudge, 2007) procura fazer articulações entre a função da linguagem para Bakhtin e Lacan. No referente aos outros cinco resultados, a tese (Luo, 2015) procura trazer diálogos beirando a subjetividade, porém efatizando a questão da perpectiva na autobiografia feminina etnica. Os outros artigos operam diálogos enfocando: a simetria pela qual as visões de Lacan e Bakhtin se separam em relação à série paradigmática (Baker, 1995); 256 a disscussão de problemas "reais" na matemática a partir dos referidos autores, e em outros pensadores tais como Zizek e Baudrillard (Gerofsky, 2010); a contraposição de ideias dialógicas e psicanalíticas através da obra de Dostoiévski (Moura-vieira, 2009).

O panorama de trabalhados escassos no tema proposto neste ensaio evidencia a relevância da discussão, que não ocorre por diletantismo teórico. Um dos sentidos do argumento pretendido é o reconhecimento da possibilidade de, em sua diferença fundamental, o dialogismo bakhtiniano servir como uma expressiva alegoria para o pensamento psicanalítico. Principalmente se pensarmos nas vicissitudes de uma subjetividade que é permanente dádiva do outro e, simultaneamente, jamais idêntica a si mesma. Neste sentido, a aproximação da psicanálise com o dialogismo dar-se-ia não pela já descartada fusão de gramáticas, mas pelo exercício de expansão das bordas do pensamento psicanalítico e pela aposta na potência da coexistência da dialética e do dialogismo na lógica psicanalítica.

Ainda, é importante destacar que é inviável uma exaustiva incursão nas semelhanças e diferenças "de família" entre os dois campos convocados ao confronto. Isto, por si só, caracterizaria uma ampla agenda de pesquisa. Buscamos, assim, articular o dialogismo com a psicanálise a partir de dois tópicos. O primeiro deles é dedicado a explicitar os sentidos de unicidade, singularidade e subjetivação na perspectiva bakhtiniana em dois 


\section{ARTIGOS}

textos - Para uma filosofia do ato (1921/1993) e Problemas da poética de Dostoiévski (1963/1981). A primeira obra foi selecionada para discutirmos o conceito de unicidade, ao passo que a segunda proporcionou destacarmos a função da polifonia na escrita de Dostoiévski, na qual a questão do enunciado e das vozes ganha especial acento. Finalmente, o segundo e último tópico do presente artigo, propõe confrontar os axiomas teóricos do psicanalista francês Jacques Lacan (1949/1998) com o dialogismo bakhtiniano (1921/1993; 1963/1981).

Destacamos que a escolha por fazer uma incursão mais extensa nas discussões bakhtinianas deu-se tendo em vista a pouca familiaridade do dialogismo nos contextos de discursos e práticas em psicanálise, bem como pela necessidade de apresentação de conceitos dialógicos e sua gramática reflexiva fundamental à discussão proposta.

\section{Bakhtin: principais noções para a discussão proposta}

Principal representante do dialogismo, o crítico literário e filósofo Mikhail Bakhtin, oferece-nos uma perspectiva singularizante e estética ao entendimento dos processos de subjetivação. Esse filósofo, a partir da perscrutação do ato criativo, lançou-se na compreensão da ação sob a ótica dialógica da relação eu-outro. A partir dessa construção, gerou uma vasta produção sobre como o sujeito dialógico atualiza-se como um devir singular do ser. De acordo com essa abordagem, a singularidade seria efeito das relações intersubjetivas, donde a unicidade do ser ${ }^{1}$ dá-se por um movimento de infindáveis diferenciações e espelhamentos. Ou seja, um permanente jogo de subversão, para a positividade das referências histórico-discursivas.

A proposição acima não é, de modo algum, nova no que o termo singularidade pode aludir de modo latu ao leitor. Entretanto, é nos modos de dotar de consistência conceitual a proposição supracitada que Bakhtin efetivamente apresenta uma rica contribuição ao problema. A referida questão será enfocada à luz de dois textos que marcadamente nos oferece uma contribuição à questão levantada. São eles: Para uma filosofia do ato (1921/1993) e Problemas da poética de Dostoiévski (1963/1981).

${ }^{1}$ Para efeito de compreensão, tomemos, por ora, o termo unicidade do ser como sua dimensão única, temporalmente irreversível e, portanto, irreproduzível dado o permanente fluir da ambiência, das relações, que constituem o próprio ser. 
Seria talvez impróprio reconhecer em Para uma filosofia do ato (1921/1993) uma escrita, por assim dizer, de teor mais "psicológico". Apontado como um dos textos mais germinais da escrita bakhtiniana (Faraco, 2003), essa obra apresenta noções fundamentais e que percorrem todos os posteriores escritos do filósofo russo. Psicológico ou filosófico ou ético, o que nos importa é a força hermenêutica que as noções ali prefiguram sobre as questões ontológicas do ser. E, em especial, aquelas que respondem de modo único ao problema da singularidade, donde decorre uma série de consequências acerca da responsabilidade e dos modos de ser.

Preocupado com as dicotomias estabelecidas pelo sujeito epistêmico - tais como, mundo da cognição teórica e mundo da vida, pensamento e realidade única e concreta - Bakhtin problematiza sobre a restauração dessas dualidades na unicidade responsável das ações de um ser que é radicalmente histórico, efeito de um evento espaço-temporal; reativo, e por isso mesmo, vivo. Em suas palavras: "Historicamente, o Ser único real é maior e mais pesado que o Ser unitário da ciência teórica, mas essa diferença em peso, que é autoevidente para uma consciência viva que a autoexperimente, não pode ser determinada em categorias teóricas" (1921/1993, p. 26).

Seria, assim, a partir do alheamento ético-histórico estabelecido por via das ciências modernas (século XIX e XX), que o autor deflagra sua narrativa sobre a impossibilidade das abstrações dessas disciplinas em darem conta da vida da ação, da vida viva. A tecnologia é posta como exemplo de um saber que, em sua autonomia de leis internas e de desenvolvimento "impetuoso, infreável" (p. 25), se esquiva de sua maior tarefa: acompanhar seu desenvolvimento na cultura e aquilo a que ela se prestaria, sendo utilizada muitas vezes "antes ao mal que ao bem" (p. 25). Em suas palavras: "[o Ser teórico] não pode oferecer nenhum critério para a vida prática, a vida da ação, porque ele não é o Ser no qual eu vivo, e, se ele fosse o único Ser, eu não existiria" (p. 27). E não existiria, uma vez que seria através do Ser evento único, temporalmente determinado, que as verdades das ciências respondem, se alimentam e consistem como fato da existência.

O propósito bakhtiniano seria, necessariamente, o da retomada da unidade inescapável do que existe no mundo enquanto algo indissolúvel da eventicidade da existência do Ser. Assim, nesse pensamento, o ato teórico deveria encontrar-se incluído como ação real da vida do Ser - numa relação de necessidade moral e responsável. A razão teórica faria parte como apenas um de seus momentos da razão prática da vida, marcada pela unicidade das ações, participativas, afetivo-volitivas, singulares e concretas do mundo. 


\section{ARTIGOS}

A dita "estetização da vida", ou ainda, "a vida-em-processo-de-devir" fariam parte do "sujeito portador do ato de visão" (p. 31), sendo o objeto estético uma parcialidade, uma produção que marcaria inescapavelmente a incompletude humana. Parcialidade porque esse ato de visão não pode ver tudo, é limitado pela posição corpórea, espaço-temporal, daquele que contempla. Em suas palavras:

A tentativa de encontrar-se a si mesmo no produto do ato-ação da visão estética é uma tentativa de lançar-se no não Ser, uma tentativa de abandonar tanto minha autoatividade do meu lugar próprio e único situado do lado de fora de qualquer ser estético, quanto sua plena realização enquanto Ser-evento. O ato realizado da visão estética se eleva acima de qualquer ser estético - um produto deste ato - e é parte de um mundo diferente: ele entra na unidade real do Ser-evento, incorporando no Ser também o mundo estético, como um momento constituinte. A pura empatia seria, de fato, uma queda do ato-ação em seu próprio produto, e isso, é claro, é impossível. (p. 34)

No contexto dessa citação, Bakhtin enfatiza o impossível da transposição/anulação da lei da localização do Ser. Isto significa dizer que seria da ordem da radical impossibilidade do olhar descolar-se da posição única que o contemplador assume no mundo (no instante real e concreto de ver) — numa fantasiosa busca de uma neutralidade extra-mundana/sobre-humana - que o produto do ato de visão dar-se-ia.

Numa de suas escritas posteriores, $O$ autor e a personagem na atividade estética (1923/2003), Bakhtin problematiza sobre como se daria a contemplação da própria vida do autor na construção de uma escrita autobiográfica. Para abarcar esse problema, à luz da indissolúvel unicidade pela qual nos é possível experienciar e criar o mundo com suas alteridades, Bakhtin lança mão de noções como transgrediência e excedente de visão. Assim o filósofo caracteriza o princípio fenomenológico desses termos:

[...] essa posição singular, a única de onde se pode perceber o todo da personagem e o mundo como algo que de fora o guarnece, restringe e acentua, fora da personagem não é atingida de modo convincente e sólido pela visão do autor em toda a sua plenitude e daí, resulta, aliás, a seguinte peculiaridade do todo artístico característica desse caso: o fundo, o mundo às costas da personagem não foi elaborado nem é percebido nitidamente pelo autor-contemplador, e é dado supostamente, de modo incerto, de dentro da própria personagem, assim como é dado a nós mesmos o fundo de nossa vida. (p. 17)

O dito fundo da nossa vida, o que fica às nossas costas, é suposto, imaginado, ou ainda criado, a partir da unicidade do ato de visão do autor; 
num exercício de pretensa exotopia. Um deslocamento operado na posição do sujeito, para a qual este se projeta sobre o olhar de um outro imaginário, uma alteridade indeterminada, mas que se prestaria a apreender a dimensão transgrediente do ângulo de visão da consciência do autor. Buscando tornar-se um outro em relação a si mesmo (eu-para-os-outros), tenta-se espreitar os pontos cegos, o desconhecido; a refração projetiva do que nos escapa e, por isso mesmo, é dotado do mais intenso valor.

A estilística existencial, ou ainda, a estetização da vida seria fortemente marcada pelo movimento de inatingível captura do que nos ultrapassa, nos excede através do olhar de um estranho que nos habita. A autoria, nessa concepção, construir-se-ia no movediço solo de uma posição sustentada na tensão entre a transgrediência valorativa (axiológica) e os destinos narrativos que produzimos para os indeterminados efeitos deste radical $^{2}$ espelhamento nos olhos dos outros. Para Clark e Holquist (2004), "self, uma atividade que nunca posso completar. De modo que o self tem de ser pensado como um projeto" (p. 97).

O objeto estético sempre traria a marca daquele que o produz em sua ação contemplativa, assim como seria dessa condição que desliza a responsabilidade do contemplador sobre aquilo que vê. Para o referido filósofo, compreender um objeto é, sobretudo, compreender o dever do sujeito-contemplador em relação a ele, compreendê-lo em relação à unicidade do meu Ser-evento. Isso nunca como uma abstração de si mesmo, de sua posição, mas, sobretudo, reconhecendo e assumindo os efeitos que podem ser produzidos nesse jogo de diferenças, nesse jogo fluido entre alteridades. Este é um dos princípios que regem a própria formação humana.

Se entendermos que nesta perspectiva a ação é uma resposta, uma responsividade natural e própria do Ser que vive a partir de um infindável campo de contingências e existe a partir de um mundo de mutáveis e evanescentes estímulos, perceberemos que o "eu" não adquire consistência "em si mesmo", fora de um ethos, de uma ambiência dialógica. É, então, como um contínuo de responsividades particulares a um meio que seria da mais intensa contingência (física, temporal, histórica, discursiva, organísmica) que nos tornamos sujeitos plenos de vida. Conforme propõe Clark e Holquist (2004), o ser seria "uma dádiva do outro" (p. 93).

Torna-se importante assinalar que a dádiva supracitada não deve ser significada como algo passivamente recebido, mas como evento vividamente participado.

${ }^{2} \mathrm{O}$ termo radical é utilizado no sentido de raiz constitutiva do processo de subjetivação. 


\section{ARTIGOS}

Tudo o que tenha a ver comigo me é dado em um tom emocional-volitivo, porque tudo é dado a mim como um momento constituinte do evento do qual estou participando. Se eu penso em um objeto, eu entro numa relação com ele que tem o caráter de um evento em processo. Em sua correlação comigo, um objeto é inseparável de sua função no processo. Mas essa função do objeto dentro da unidade do evento real que nos abrange é o seu valor real, afirmado, isto é, é o seu tom emocional-volitivo. (Bakhtin, 1923/2003, p. 51)

Neste sentido, participar implica a inevitável responsividade pró-ativa do ser naquilo que ele experimenta como dado. O ser - que se constitui entre o lócus único de sua responsividade vital e o ambiente alteritário (natural e cultural) do qual faz parte - autora na sensibilidade pela qual apreende o outro, sua ação criativa. O tom emocional-volitivo, no texto bakhtiniano, parece aludir à realidade encarnada, entoada nas palavras enunciadas pelo outro. Isto performatizaria tudo aquilo que excede e, ao mesmo tempo, torna-se indissolúvel do universo simbólico através do qual nos constituímos. No que se refere, portanto, à pró-atividade do vivido, Bakhtin (1921/1993), todavia adverte:

[...] eu posso ignorar minha autoatividade e viver apenas pela minha passividade. Eu posso tentar provar meu álibi no Ser, eu posso pretender ser alguém que não sou. Eu posso abdicar da minha obrigatória (dever ser) unicidade. Um ato ou ação responsável é precisamente aquele ato realizado sob a base de um reconhecimento de minha obrigatória (dever-ser) unicidade. É essa a afirmação do meu não álibi no Ser que constitui a base da minha vida sendo tanto real e necessariamente dada como também sendo real e projetada como algo-ainda-por-ser-alcançado. É apenas o meu não álibi no Ser que transforma uma possibilidade vazia em um ato ou ação responsável e real. (p. 60)

O não álibi no Ser parece realçar a dimensão ética das proposições bakhtinianas. Essa noção, central ao texto, reitera a preocupação sobre os efeitos da ação criativa, implicando a filosofia moral de Bakhtin, a consequência inescapável da unicidade da existência. O algo-ainda-por-ser-alcançado deflagraria o permanente "porvindouro" das ações, num movimento de tensão ante a responsabilidade e a constante invenção de si (Bakhtin, 2003). Assim, esse filósofo também tenta diluir qualquer entendimento do ser como unidade, individualidade, centro ou núcleo egoico. O ser, movido e constituído através de infinitas alteridades não seria encontrável por ele mesmo. Em suas palavras: "O fato de minha participação única e insubstituível no Ser é entrar no Ser precisamente onde ele não coincide com ele mesmo: entrar no evento em processo do Ser" (p. 60). 
É notório que a presente seção apenas recorta uma fração dos infinitos cenários filosóficos que podemos encontrar na leitura de Para uma filosofia do ato. Nessa obra, de acordo com Faraco (2003):

[...] a linguagem aparece já apresentada como atividade (e não como sistema) e o enunciado como um ato singular, irrepetível, concretamente situado e emergindo de uma atitude ativamente responsiva, isto é, uma atitude valorativa em relação a um determinado estado-de-coisas. (p. 24)

Desse modo, a linguagem é enquadrada como amálgama indissolúvel da alteridade constitutiva do Ser. Para o filósofo, seriam as vozes do outro, como uma formação discursiva marcada pela contingência sócio-histórica, o componente central da subjetividade dialógica por ele argumentada.

Em Problemas da poética em Dostoievski (1963/1981), a questão da linguagem torna-se dimensão destacada, pois nela encontramos a emergência da palavra viva. Isto é, da palavra tornada discurso enunciado por um autor que se constitui num permanente e infinito diálogo junto ao outro. Uma extensa gama conceitual é problematizada a partir da literatura e, assim, no argumento em defesa da riqueza polifônica do romance em Dostoievski, da "não uniformidade" (p. 158) da linguagem; Bakhtin problematiza o ângulo estritamente dialógico por onde a escrita dostoievskiana se constrói. Afirma o autor:

A ideia, como considerava o Dostoievski-artista, não é uma formação psicológico-individual subjetiva com "sede permanente" na cabeça do homem; não, a ideia é um acontecimento vivo, que irrompe no ponto de contato dialogado entre duas ou várias consciências. Neste sentido a ideia é semelhante à palavra, com a qual forma uma unidade dialética. Como a palavra, a ideia quer ser ouvida, entendida e "respondida" por outras vozes e de outras posições. Como a palavra, a ideia é por natureza dialógica [...]. (p. 73)

O elogio de Bakhtin à obra de Dostoievski perpassa, assim, pela natureza de sua escrita. Natureza esta para qual a ideia $^{3}$ e as palavras não existem sem a ideia e a palavra dos outros. Ambas apenas ganhariam vida em relação a outras, estabelecendo um jogo de inter-ânima. Assim sendo, o sopro de vida delas emerge na relação com outras vozes ou outras consciências. Em

${ }^{3}$ Não se deve tomar o termo ideia, no texto de Bakhtin, como formação metafísica de uma genialidade racional. O termo ideia comporia, de modo geral, o vocabulário sobre o ideológico; designando as produções imateriais, espirituais, sociais, valorativas, da cultura. Como toda formação ideológica é significada, tudo que seria ideológico possuiria valor semiótico, numa relação de co-incidência sígnica (Faraco, 2003). 


\section{ARTIGOS}

contrapartida, a morte da ideia aconteceria quando esta se isolaria na consciência de um homem. "Somente quando contrai relações dialógicas essenciais com as ideias dos outros é que a ideia começa a ter vida, isto é, a formar-se, desenvolver-se, a encontrar e renovar sua expressão verbal, a gerar novas ideias" (ibidem.)

Seria nesse sentido que os signos, para o Círculo de Bakhtin, refratam o mundo, uma vez que o processo de significação não é dado como num glossário transcendental ou gramática de regras fixas e atemporais. Muito pelo contrário, o processo de significação, como ação humana, seria uma construção dinamizada pela história de um povo, pela experiência dos falantes, pela unicidade do enunciador, pelas infinitas vozes sociais através das quais atribuímos sentindo ao mundo. "Em outras palavras, a refração é o modo como se inscrevem nos signos a diversidade e as contradições das experiências históricas dos grupos humanos" (Faraco, 2003, p. 50).

Dessa forma, todo dizer seria, assim, uma resposta a um já dito de nosso universo discursivo; uma expectativa de réplica a um destinatário (uma outridade constitutiva); uma heterogeneidade de natureza dialógica dada às infinitas vozes histórico-culturais, às infinitas alteridades que se confrontam e se atualizam (ato) no enunciado do sujeito (ibidem). Nas palavras de Bakhtin:

Enquanto artista, Dostoievski não criava as suas palavras do mesmo modo como criam os filósofos ou cientistas; ele criava imagens vivas de ideias auscultadas, encontradas, às vezes advindas por ele na própria realidade [...] auscultava a sua época como um grande diálogo, de captar nelas não só vozes isoladas, mas, antes de tudo, as relações dialógicas entre as vozes, a interação dialógica entre elas. Ele auscultava também as vozes dominantes, principais (oficiais e não oficiais), bem como vozes ainda fracas, ideias ainda não inteiramente manifestas, ideias latentes ainda não auscultadas por ninguém exceto por ele e ideias que apenas começavam a amadurecer, embriões de futuras concepções do mundo. (p. 75)

O fascínio de Bakhtin por essas características da escrita de Dostoievski estampava sua refração sobre a magnitude dessa literatura. Em sua leitura da obra, Bakhtin reconhecia a encenação da mais plena potência dialógica que um texto poderia ter. A tão discutida noção de polifonia é tomada no texto como atributo gerado pelo romance de Dostoievski. Como pode ser inferido na citação acima, o traço distintivo de uma construção polifônica não ocorreria como expressão de muitas vozes (o que seria um pressuposto básico da consciência), mas como universo em que a multiplicidade de vozes assumem a mesma força/poder (equipolente), como numa radical e utópica 
democracia, em que consciências independentes e intransponíveis coexistem num infindável diálogo.

É no cenário dessa discussão que podemos nos aproximar da questão da carnavalização da literatura. Nessa graciosa alegoria vislumbrada por Bakhtin, o carnaval ("esta vida desviada de sua ordem habitual, em certo sentido uma 'vida às avessas', um 'mundo invertido"”; p. 105) é transposto como metáfora das forças subversivas — de desterritorialização dos discursos autoritários (de traço monológico) — impulsionadoras da produção do novo nas artes literárias, especialmente numa perspectiva dialógica. Os símbolos carnavalescos como a descoroação do rei, a profanação, a excentricidade, são reconhecidos como alegorias que na literatura refletiriam o lugar da mudança e da transformação, da morte e da renovação (p. 107).

A coroação-destronamento é um ritual ambivalente biunívoco, que expressa a inevitabilidade e, simultaneamente, a criatividade da mudança-renovação, a alegre relatividade de qualquer regime ou ordem social, de qualquer poder e qualquer posição (hierárquica) [...] E assim são todos os símbolos carnavalescos: estes sempre incorporam a perspectiva da negação (morte) ou o contrário. $\mathrm{O}$ nascimento é prenhe de morte, a morte, de um novo nascimento. (ibidem)

O carnaval, como uma "cosmovisão viva" desvelaria, em sua potência anárquica, o sonho, a utopia, de superação de qualquer monologização da existência. Nesse cenário, as forças centrípetas dos discursos sociais estabelecidos, de estancagem do fluxo semiótico, se afrouxariam sob a intensidade centrífuga das refratárias e singularizantes redescrição das criações ideológicas.

Trazendo essa reflexão para o plano da autoria, recorro a Faraco (2003) que assim a define: "assumir uma posição estratégica no contexto da circulação e da guerra das vozes sociais é explorar o potencial da tensão criativa da heteroglossia dialógica; é trabalhar nas fronteiras" (p. 83).

\section{Bahktin e Lacan: um confronto necessário}

A partir de sua gênese clínica, o legado de Freud e Lacan oferece-nos um significativo universo de problematizações sobre as contingências do tornar-se sujeito num determinado tempo histórico, abarcando as especificidades estruturantes da lei, do simbólico, através das quais a subjetividade singulariza e reinventa o seu devir. É nesse sentido que Rorty (2007) realiza seu elogio à 


\section{ARTIGOS}

psicanálise, enquanto uma metáfora que permitiu uma descrição humana nunca antes experimentada. Em suas palavras:

Começamos a compreender o papel de Freud em nossa cultura quando o vemos como o moralista que ajudou a desdivinizar o eu, ao rastrear a consciência até sua origem nas contingências de nossa criação [...] Isso porque a descrição freudiana da fantasia inconsciente mostra-nos como ver toda a vida humana como um poema - ou, mais exatamente, toda a vida humana como não destroçada pela dor que não possa apreender uma linguagem, nem tão imersa no trabalho que não tenha tempo de gerar uma descrição de si mesma. Freud considera que cada vida é uma tentativa de se revestir de suas próprias metáforas. (pp. 72-73)

Antes de adentrarmos na especificidade da aproximação, torna-se necessário levantar as críticas que Bakhtin produziu ao Freud que lhe foi possível ler em sua época. Expressando seu repúdio à concepção do sujeito sexual na psicanálise, contesta Bakhtin (2007):

Assim, o essencial no homem não é, de maneira nenhuma, aquilo que determina o seu lugar e seu papel na história - a classe, a nação, a época histórica que ele pertence; essenciais são apenas o seu sexo e a sua idade; tudo o mais é mera superestrutura erigida sobre esses elementos. A consciência do homem não é determinada pelo seu ser histórico, mas pelo ser biológico, cujo aspecto fundamental é a sexualidade. (p. 6)

$\mathrm{Na}$ interpretação de Bakhtin, o discurso freudiano era tomado como protótipo do esvaziamento sócio-histórico do homem. A crítica reducionista, caricatural e mordaz à psicanálise baseou-se numa época (1927) caracterizada pelo forte radicalismo ideológico na produção do conhecimento científico. $\mathrm{O}$ axioma do pertencimento de classe se configurava como matriz de diversas áreas do saber, da filosofia às artes, à fisiologia. Segundo Bezerra (2007): “Ao clima de exacerbação ideológica, caldo de cultura propício a toda sorte de reducionismos, soma-se a extrema fragilidade da psicologia russa" (p. vii).

O autor destaca ainda que, até então, os atendimentos de natureza psicológica eram de competência médica, psiquiátrica. A psicologia seria um campo estritamente acadêmico, sem muita articulação com os contextos pragmáticos da vida humana. O empenho, portanto, de diversas abordagens psicológicas na Rússia Soviética era o de produzir uma psicologia como ciência objetiva (ibidem), livre de quaisquer formas de compreensão individualistas, biologizantes, subjetivistas. Nesse contexto, emergia uma concepção de que o sujeito existe de modo historicamente real e culturalmente produtivo como 
partícipe da classe social, ou, ainda, como efeito do conjunto das relações sociais.

Dessa forma, a leitura bakhtiniana da escrita de Freud aparenta ter sido permeada pela surpresa e pela recusa de uma narrativa que mergulharia nas idiossincrasias páthicas e na história individual de modo tão extensivo. As teorias do médico vienense oitocentista foram tomadas, assim, num espelhamento às avessas, como o protótipo da ideologia burguesa, vitoriana, europeia a ser combatida/refutada. Essa tradição distorceria as raízes materiais-objetivas da subjetividade, transformando-as em motivações biológico-instintivas e individuais, o que desresponsabilizaria o homem de suas relações com a classe, com a sua pró-atividade histórica; com a possibilidade de um sentido mais amplo do seu existir, que não apenas um joguete de motivações sexuais. A ótica imposta sobre o texto freudiano dá-se através da reivindicação do lugar da vontade. Vislumbra-se, com isso, que certa lente do materialismo histórico-dialético, de tradição marxista, teria sido colocada sobre o texto psicanalítico.

Entre a retenção das fezes e a retenção do dinheiro, entre as fezes e o ouro, existe apenas uma semelhança subjetiva bastante forçada, por assim dizer, uma semelhança de impressões, mas não há quaisquer fios materiais e reais que as vinculem na composição material do próprio organismo e do seu ambiente, isto é, que as vincule na experiência objetiva. (Bakhtin, 2007, p. 72)

Página por página, $O$ freudismo tenta demolir, tijolo a tijolo - do método à própria concepção do inconsciente -, o edifício psicanalítico que bradava aos quatro ventos na Europa ocidental, começando também a reverberar na União Soviética marxista-leninista da época. A psicanálise, contudo, parecia ter ofendido o âmago dos ideais soviéticos, visto que Freud parecia oferecer uma imagem de subjetividade mesquinha em seu narcisismo infantil, vulnerável à força de suas pulsões, permanente frustrada em suas fantasias pelo princípio da realidade. O freudismo, então, operava, assim, um diálogo de surdos, posto que a letra freudiana não era compreendida em sua radicalidade.

Ainda que Bakhtin nunca tenha se declarado marxista, este seria o cenário cultural de seu tempo, que inevitavelmente participou de suas elaborações. Sob o ângulo estrito dessa obra bakhtiniana, psicanálise e dialogismo seriam efetivamente incomensuráveis; mais que isso, antagônicos. Entretanto, seria equivocado tomar o precipitado dessa crítica, formuladas sem o apoio de textos mais culturalistas da escrita freudiana, assim como sem o posterior incremento da leitura de Lacan (1949/1998). Essa espécie de "judas" a que a metapsicologia se prestou, na caricatura demolidora do dialogismo, pode ser 


\section{ARTIGOS}

pensada como apenas uma das refrações possíveis sobre a aproximação entre a perspectiva bakhtiniana e a psicanálise. Segundo Novaes e Rudge (2007):

$\mathrm{Na}$ verdade, apesar do fato de que a psicanálise, que é uma prática clínica teorizada, e a filosofia da linguagem de Bakhtin serem campos tão diversos, há fortes coincidências entre as concepções de linguagem entre Bakhtin e Lacan. Embora as leituras dos primeiros textos fundamentais da psicanálise empreendida pelos dois autores sejam inteiramente divergentes, mostraremos que as concepções de Lacan e Bakhtin sobre a linguagem confluem. (p. 161)

A concepção de "confluência" acima aludida é, no mínimo, problemática. É dessa imprecisão que a noção de semelhança de família pode nos auxiliar a não incorrer. Ao longo deste texto será exposta a impossibilidade de se assumir "um encontro" entre as perspectivas, e sim uma "semelhança de família" (Wittgenstein, 1999), como tem-se argumentado.

De acordo com a compreensão das autoras supracitadas, a interface de aproximação dos dois discursos ocorreria através de três pontos: a linguagem como constitutiva e anterior ao advento do sujeito; a função da alteridade nos processos enunciativos e, por fim, como uma decorrência, a compreensão da linguagem - que composta por signo/sistema/código — é apreendida pelas duas epistemes em sua condição de "acervo coletivo que pode ser subvertido pelo ato do sujeito" (Novaes \& Rudge, 2007, p. 174). Tais proposições colocadas a chofre podem gerar controversas, haja vista a extensão e os distintos propósitos das escritas nas duas abordagens.

Pode-se dizer que os supostos três pontos de convergência referidos apenas se assemelhariam se fizéssemos uma apreensão mais horizontal do que viria a ser a linguagem para cada perspectiva. A concepção lacaniana do simbólico não se restringe ao cômputo descritivo do sistema sígnico. $\mathrm{O}$ legado de Lacan, tanto na linguística quanto na psicanálise, percorre desde a separação entre significante e significado do signo proposto por Saussure (2004), à autonomia/precedência do significante sobre o significado, até os efeitos que o grande Outro (a estrutura significante de leis próprias) provocaria no processo de subjetivação de um ser dividido.

Colocado dessa forma, a posição da episteme bakhtiniana, em seu estatuto de diferença para com Lacan, foca a linguagem em seu efeito de sentido, como processo de significação determinado pelos contextos enunciativos, de natureza dialógica entre os falantes. Bakhtin estaria muito mais próximo ao pragmatismo da linguagem. Nessa compreensão, a ênfase dá-se na contingência de uma linguagem que não possui leis próprias, mas regras empreendidas nas ações dos sujeitos participantes de uma determinada forma 
de vida. Diferenciando-se do dialogismo, o pós-estruturalismo lacaniano acentua a exterioridade e a autonomia do simbólico e seus efeitos em relação ao devir do ser (sujeito da falta).

Antes de nos aprofundarmos nos efeitos desta raiz diferenciadora entre os dois autores, caberia indagar sob que condições seria produzida a "ilusão" de semelhança entre as perspectivas em discussão. Sob que ângulo narrativo tornar-se-ia possível, conforme sugerido por Novaes e Rudge (2007), produzir a ficção de convergência entre tradições tão distintas?

No esforço de realizar uma apreensão crítica sobre os encaminhamentos que as referidas autoras desenvolvem para tais questões, examinaremos uma citação de Bakhtin a partir da qual se desenvolveu o dilemático artigo propositor da aproximação ora questionada.

Tudo o que me diz respeito, a começar pelo meu nome, chega do mundo exterior à minha consciência pela boca dos outros (da minha mãe etc.), com sua entonação, em sua tonalidade valorativo-emocional. A princípio eu tomo consciência de mim através dos outros: deles recebo as palavras, as formas e a tonalidade para a formação da primeira noção de mim mesmo. (Bakhtin, apud Novaes \& Rudge, 2007, p. 174)

Essa citação, aos olhos das autoras - mais interessadas no delicado jogo de semelhanças entre Bakhtin e Lacan — reconheceriam nessa passagem o compartilhamento da concepção de que toda palavra que pronunciamos adviria do simbólico, sendo a outridade, encarregado da maternagem, um dos seus representantes. Se insistirmos em forçar as coincidências, poderíamos até incrementar com a leitura de Clark e Holquist (2004) que destacam o lugar do olhar nessa metáfora bakhtiniana. Os autores afirmam que: “[...] a refração do mundo através dos valores de outrem começa muito cedo, quando as crianças principiam a enxergar-se através dos olhos de suas mães, e ele prossegue durante a vida inteira" (p. 97).

No pensamento lacaniano, a alteridade como condição da constituição subjetiva é apresentada por Lacan, em comunicação no XVI Congresso Internacional de Psicanálise (1949/1998), sob a seguinte formulação:

$\S 07 / 33$. A assunção jubilatória de sua imagem especular por esse ser ainda mergulhado na impotência motora e pela dependência da amamentação pelo homenzinho neste estádio de infans parecer-nos-á pois manifestar, numa situação exemplar, a matriz simbólica onde o $[e u]$ precipita-se em forma primordial, antes de se objetivar na dialética da identificação ao outro e antes que a linguagem lhe restitua, no universal, sua função de sujeito. (p. 99)

No artigo intitulado $O$ estágio do espelho como formador da função do eu tal como nos é revelada na experiência psicanalítica (1949/1988), Lacan 


\section{ARTIGOS}

destaca a importância da dialética social nesse processo, e, ainda, como um elemento fundamental na perspectiva psicanalítica. Entretanto, o mergulho desenvolvido nessa citação se empenha, sobretudo, na apresentação dos fundamentos da produção da imago ante a imaturidade, até mesmo fisiológica, do ser.

Desse modo, as duas citações acima aludidas encontrariam como semelhança a função do espelhamento na constituição da subjetividade. Tanto em Lacan quanto em Bakhtin observa-se a recorrência à relação de espelhamento como uma referência para tematizar o tornar-se sujeito em ambas abordagens. Entretanto, seria unicamente sob esse ponto que se iniciaria e terminaria o imaginado "encontro". Na referência à figura do espelho isso significa dizer que entre o espelho bakhtiniano e a especularidade lacaniana, um vertiginoso abismo teórico-epistemológico é vislumbrado.

Uma série de elementos poderia ser apontada para marcar essa diferença, tais como a questão pulsional envolvida na especularidade lacaniana, a função da imago na subjetivação, ou o sentido de consciência em Bakhtin. Contudo, dos vários recortes possíveis para o trabalho de diferenciação, escolhese os sentidos de outro e Outro em psicanálise, como um princípio que nos auxilia a não cairmos nas armadilhas e confusões que esses termos podem gerar quando nos deparamos com abordagens que se amparam na alteridade simbólica como fundamento da subjetividade. De acordo com Guerra e Carvalho (2006):

Nessa perspectiva [lacaniana], o outro foi concebido como nosso parceiro do cotidiano, porém tecido com os fios do imaginário, ou melhor, fios que vêm de nós, através do nosso semelhante, dado o caráter especular da relação imaginária. Por sua vez o Outro foi concebido por Lacan como aquele que se distingue do parceiro imaginário (outro), por se constituir como a ordem da linguagem/ simbólico, isto é, lugar do significante, lugar da lei. Uma tal ordem seria anterior e exterior ao sujeito que a ela estaria, radicalmente, submetido. (p. 50)

Apesar de nosso atravessamento pelo simbólico ser possível apenas através dos nossos representantes, o outro, essa diferenciação instaura uma radical diferença entre os pressupostos das abordagens postas em diálogo. Isto implica afirmar que, de acordo com a psicanálise, o Outro (grande outro), como registro da lei simbólica - que é em nós inscrita através do vínculo primordial —, instaura um corte fundante no inconsciente do sujeito. Nesse sentido, essa questão não trata apenas do campo de uma "apropriação" da língua, mas, sobretudo, da operação de corte/divisão do sujeito, instaurador da falta constitutiva e do advento do sujeito desejante. 
Em Bakhtin, o outro é colocado como alteridade da natureza do ser. Mas não, contudo, uma natureza intersubjetiva. Essa intersubjetividade também será suspensa/questionada na epistemologia psicanalítica, uma vez que o inter, como noção que aludiria a um encontro dos sujeitos na linguagem, nos ditos, é assumida como impossível. Seria uma produção especular, eternamente frustrada pelo lugar do terceiro, do código que fratura qualquer ilusão do mesmo. Acreditamos que seria especialmente nesse ponto em que não podemos falar de "confluência" entre Lacan e Bakhtin, e sim de uma diferença instauradora da singularidade desses discursos, no entanto provocadora de fortes alegorias hermenêuticas para a reflexão desses campos conceituais. Em outras palavras, a radical diferença pode também nos oferecer metáforas favorecedoras da inquirição sobre a singularidade e a constituição subjetiva tão importantes não só à psicanálise, mas também a todos que se debruçam sobre a pesquisa e as práticas voltadas para o tornar-se sujeito nos nossos dias.

Outro tópico diferenciador das abordagens em arguição refere-se à questão da consciência em Bakhtin e o inconsciente segundo Lacan. O inconsciente, no contexto da própria psicanálise, é passível de diversas versões. Do inconsciente freudiano ao estrutural, até mesmo ao inconsciente descrito sob o ponto de vista pragmático (Bezerra, 1994), intensas seriam as variações encontradas. Do conteiner libidinal ao dinamismo significante, novas metáforas, novas imagens do sujeito são produzidas.

Mesmo podendo reconhecer a pluralidade de leituras sobre o que chamamos de inconsciente, um ponto de estofo que participaria da vasta gama de enunciados abrigados pelo conceito configura-se na imagem de uma subjetividade dividida e que tem seu dinamismo "operando permanentemente sob o modo de conflito e estabilizações provisórias" (Bezerra,1994, p. 157).

Longe de situar tal regra como núcleo que responde à inteireza das diversas conceitualizações sobre o inconsciente; a colocação assim referida apenas alude a um traço convencionado sob a rubrica psicanalítica. Esse traço, no argumento ora levantado, abre caminho para o entendimento de que é do sujeito do não controle que a psicanálise constrói sua reflexão.

Nesse sentido, o texto bakhtiniano, numa decorrência acerca da inalienável condição formativa do outro, desenvolve uma descrição da subjetividade como dinamizada pela heteroglossia. Essa noção configura o permanente embate de diversas vozes que participariam da consciência individual. Tal "guerra de discursos" (Faraco, 2003) espelharia as infindáveis possibilidades de refração do mundo, o múltiplo universo de verdades sociais que estão "materializadas semioticamente e redundam em diferentes vozes ou línguas 


\section{ARTIGOS}

sociais" (p. 107). Os sujeitos seriam atravessados por uma permanente e tensa heterogeneidade dialógica, um jogo de forças centrípetas (de centralização, monologização do discurso) e forças centrífugas (de resistência às forças monologizadoras, multiplicadoras da heteroglossia).

Assim, por consciência no discurso de Bakhtin, não devemos presumir as heranças filosóficas de racionalidade, nem um centro gerenciador de discursos, muito menos uma arquitetura lógica dos processos subjetivos. Muito pelo contrário, o sujeito em Bakhtin é aquele que existe apenas através do caldeirão tenso e diverso de enunciados, que se interanimam numa constante responsividade valorativa a um já dito. O tom volitivo-emocional, expressão muito utilizada pelo filósofo, parece capturar a dimensão viva, aquém e além da estrutura, naquilo que pode ser performatizado no discurso. Torna-se, portanto, problemático situar a obra bakhtiniana no campo dos vocabulários acerca do sujeito do controle. Conforme sintetizam sob a ótica dialógica Clark e Holquist (2004.): "Quando desenvolvo consciência de mim mesmo, não é como uma crescente percepção de alguma coisa, mas antes como uma "consciência do fato de que eu, no meu aspecto mais fundamental de mim próprio, não sou ainda"” (p. 97).

Para além dessa proposição, o modelo que Freud construiu remete-nos a uma condição subjetiva descentrada, desprovida de qualquer positividade do "eu sou". O sujeito seria pura diferença em relação a si próprio. "Ele só pode se manifestar "para si' negando-se tal qual é 'em si"” (Lacan, apud Bezerra, 1994, p. 35). Retomando a metáfora estrutural, o sujeito "seria aquilo que um significante representa para outro significante" (ibidem), movimentando a cadeia significante num jogo de semelhanças e diferenças produtoras de significação, de efeitos de subjetivação.

Se tanto Lacan quanto Bakhtin não abordam a subjetividade pelo ângulo do sujeito do controle, encontraríamos nesse aspecto um ponto comum? À primeira vista, a resposta seria não, pois entre o sujeito do inconsciente e o sujeito dialógico, as implicações teórico-interpretativas são bastante distintas. No dialogismo bakhtiniano, a problematização sobre singularidade teria como foco/acento os sentidos, os repertórios interpretativos através dos quais os sujeitos buscariam autorar a unicidade dinâmica e heteroglótica de sua subjetividade. Em outras palavras, através do texto de Bakhtin, haveria uma ênfase discursivista nas vozes sociais que dialogariam, de modo conflitivo, com uma singularidade valorativamente enunciada. Já na perspectiva lacaniana, além de não ser possível pensar num eu habitado por vozes, uma vez que o eu é o Outro (Lacan, 1949/1998), o estudo da singularidade desloca-se de uma postura de ênfase no sentido discursivo-pragmático dos falantes sobre o tema, e passa a problematizar acerca de suas articulações reais, simbólicas 
e imaginárias, sobre uma subjetividade constituída a partir da alienação ao outro.

No entanto, conforme discutido ao longo da escrita, pretendemos não só apontar o terreno de diferenciação necessária, mas, sobretudo, nos beneficiar de um delicado trabalho de aproximação, potencializador do reconhecimento da singularidade humana e dos versionamentos da alteridade na formação do sujeito.

\section{Considerações finais}

Através do percurso argumentativo produzido no presente artigo, propomos em síntese que tanto a perspectiva bakhtiniana quanto a lacaniana podem produzir um profícuo diálogo a partir das metáforas conceituais que cada uma lança mão na compreensão da constituição do sujeito.

Nesse sentido, destacamos como efetivas dimensões de aproximação entre estes dois terrenos discursivos os seguintes aspectos ontológico-epistemológicos: 1) a partilha da concepção de um sujeito que não é, em si mesmo, desprovido de qualquer essência ou possibilidade de positivação; 2) a gênese

272 alteritária da subjetividade — embora na psicanálise através da dinâmica do Grande Outro formativo do estágio do espelho e, no dialogismo, a alteridade provocada pelo excedente de visão, bem como a necessidade estética absoluta do outro; 3) a gramática do não controle como marca fundamental de um sujeito cuja relação com o mundo é sempre conflitiva, permeada por um incessante jogo de forças - sejam elas pulsionais ou de vozes sociais (centrífugas ou centrípetas); 4) O lugar da inexorável implicação da singularidade do sujeito em sua relação com o mundo e a esfera das escolhas - seja pela ética do desejo ou pelo lugar do não-álibi-no-ser.

Nesse contexto, a semelhança de família (Wittgenstein, 1999) acima apontada não necessariamente se configura como uma ilusão platônica. Conforme dito anteriormente, o propósito de tal exercício aproximativo é o de favorecer o trânsito dialógico de metáforas e alegorias que favoreçam a ampliação do olhar tanto para a psicanálise quando para o dialogismo, como se uma pudesse ser o excedente de visão da outra. Podemos assim propor uma dimensão dialógica para psicanálise e uma face analítica para concepção de sujeito no dialogismo.

Para finalizar, torna-se válido mais uma vez enfatizar que o ponto de ruptura entre a aproximação proposta dá-se na concepção de linguagem, essas sim são incompatíveis, inconciliáveis, incomensuráveis. Tal diferença nos alerta que o lugar da metáfora proposta não é o de tomar uma abordagem pela 


\section{ARTIGOS}

outra, num "Frankenstein epistemológico-hermenêutico", mas o de arejar e expandir o horizonte das reflexões e dos trânsitos possíveis entre dialogismo e psicanálise.

\section{Referências}

Ascroft, E. (2016). Decentering the dialogic: Lacan with Bakhtin. The Dostoievsky Journal, 17(1), 24-43.

Baker, H. S. (1995). Psychoanalysis and ideology: Bakhtin, Lacan and Zizek. History of European Ideas, 20(1-3), 499-504.

Bakhtin, M. (1993). Para uma filosofia do ato. Tradução não publicada de Carlos Alberto Faraco e Cristóvão Tezza. (Trabalho original publicado em 1921).

Bakhtin, M. (2003). O autor e a personagem na atividade estética. In Estética da criação verbal (4a. ed.; pp. 3-90). São Pauto, SP: Martins Fontes. (Trabalho original publicado em 1923).

Bakhtin, M. (1981). Problemas da poética de Dostoievski. Rio de Janeiro, RJ: Forense-Universitária. (Trabalho original publicado em 1963).

Bakhtin, M. (2007). O freudismo. São Paulo, SP: Perspectiva.

Bakhtin, M. (2003). Arte e responsabilidade. In Estética da criação verbal (4a ed.; pp. XXXIII- XXXIV). São Paulo, SP: Martins Fontes.

Bezerra Jr., B. (1994). Descentramento e sujeito: versões da revolução copernicana de Freud. In A paixão da linguagem. Processos de subjetivação contemporâneos: Uma leitura de Clarice Lispector. Tese de Doutorado apresentada ao Instituto de Medicina Social da Universidade do Estado do Rio de Janeiro, 1996.

Bezerra, P. (2007). Freud à luz de uma filosofia da linguagem. In M. Bakhtin, $O$ freudismo. São Paulo, SP: Perspectiva.

Clark, K.; Holquist, M. (2004). Mikhail Bakhtin. São Paulo, SP: Perspectiva.

Faraco, C. A. (2003). Linguagem e diálogo: as ideias linguísticas do círculo de Bakhtin. Curitiba, PR: Criar Edições.

Gerofsky, S. (2010, fev). The impossibility of 'real-life' word problems (acording to Bakhtin, Lacan, Zizek and Baudrillard). Discourse: Studies in the Cultural Politics of Education. 31(1), 61-73.

Guerra, A. G.; Carvalho, G. M. M. (2006). A singularidade como efeito da fala na relação: um lugar de equívoco. Rio de Janeiro, RJ: Garamond.

Lacan, J. (1998). O estádio do espelho como formador da função do eu, tal como nos é revelada na experiência psicanalítica. (V. Ribeiro, Trad.). In Escritos (pp. 
96-103). Rio de Janeiro, RJ: Jorge Zahar. (Trabalho original publicado em 1949). Lacan, J. (1998). Escritos. Rio de Janeiro, RJ: Jorge Zahar. (Trabalho original publicado em 1966).

Luo, X. (2015). Living Between Dialectics: A Bakhtinian and Lacanian Reading of Jade Snow Wong's Fifth Chinese Daughter and Maxine Hong Kingston's The Woman Warrior. 465p. Tese para Illios State University.

Moura-Vieira, M. A. (2009). Bakhtin e Freud em diálogo com Dostoiévski. Bakhtiniana, 1(2), 65-79, $2^{\circ}$ sem.

Novaes, B.; Rudge, A. M. (2007). A função da linguagem em Bakhtin e Lacan. Tempo psicanalítico, 39, 157-178.

Rorty, R. (2007). Contingência, ironia e solidariedade. São Paulo, SP: Martins.

Saussure, F. (2004). Curso de linguística geral (26a ed.). São Paulo, SP: Cultrix.

Wittgenstein, L. (1999). Investigações filosóficas. (José Carlos Bruni, trad.). São Paulo, SP: Nova Cultural.

\section{Resumos}

(Limits and possibilities of an interlocution between Bakhtinian dialogism and psychoanalysis)

Based on the practice of analyzing notions such as singularity, language and otherness, the present paper discusses the possibility of establishing "language games" and "family similarities" between the Bakhtinian and Lacanian perspectives, as well as highlight their differences. This attempt is based on the recognition of a dialogical principle in psychoanalysis, from its theorization about the constitution of the subject. On the other hand, a reading of Bakhtin's texts that is inspired by psychoanalysis also puts new versions of the notion of consciousness into perspective, beyond the grammar of the subject, control and rationalism. This paper suggests that while on the one hand it would be controversial to establish a "confluence" between Bakhtin and Lacan, on the other hand, the differences may illuminate and generate new metaphors between the two approaches.

Key words: Bakhtin, Lacan, singularity, language, otherness

(Limites et possibilités d'interlocution entre le dialogisme bakhtinien et la psychanalyse)

À la lumière de la recherche sur des notions telles que singularité, langage et altérité, cet article vise la possibilité d'établir des «jeux de langage» et des "similitudes familiales» entre les postulats de Bakhtin et ceux de Lacan, ainsi que d'identifier leurs 


\section{ARTIGOS}

différences. Cette tentative repose sur la reconnaissance d'un principe dialogique en psychanalyse, à partir de sa théorisation de la constitution du sujet. D'autre part, la lecture des textes de Bakhtin, inspirée par la psychanalyse, offre également de nouvelles perspectives sur la notion de conscience, au-delà de la grammaire du sujet, du contrôle et du rationalisme. Si d'une part il est difficile d'indiquer une "confluence» entre Bakhtin et Lacan, d'autre part, ce sont les différences qui peuvent éclairer et créer de nouvelles métaphores entre les deux approches discutées.

Mots clés: Bakhtin, Lacan, singularité, langage, altérité

(Límites y posibilidades de interlocución entre el dialogismo bajtiniano y el psicoanálisis)

El presente artículo buscó - a la luz del escrutinio de nociones como la singularidad, el lenguaje y la alteridad - problematizar sobre la posibilidad de establecer "juegos de lenguaje" y "semejanzas de familia" entre las premisas bajtinianas y lacanianas, además de señalar sus diferencias. Este intento se basa en el reconocimiento de un principio dialógico en el psicoanálisis, desde su teorización sobre la constitución del sujeto. Por otro lado, la lectura de los textos bajtinianos, inspirada por el psicoanálisis, también plantea nuevas versiones de la noción de conciencia, además de la gramática del sujeto del control y del racionalismo. Se propone que, si por un lado es problemático indicar una "confluencia" entre Bajtín y Lacan, por otro son las diferencias las que pueden iluminar y generar nuevas metáforas entre los dos abordajes discutidos.

Palabras clave: Bajtín, Lacan, singularidad, lenguaje, alteridad

(Grenzen und Möglichkeiten der Kommunikation zwischen Bakhtins Dialogismus und der Psychoanalyse)

Der vorliegende Artikel versucht, aufgrund der Untersuchung von Begriffen wie Singularität, Sprache und Alterität, die Möglichkeit zu diskutieren, ,,Sprachspiele “ und „Familienähnlichkeiten“ anhand der Prämissen von Bakhtin und Lacan zu erstellen und ihre Unterschiede festzustellen. Dieser Versuch beruht auf der Annahme eines dialogischen Prinzips, das in der Psychoanalyse mit der Theorie über die Konstitution des Subjekts erscheint. Andererseits ermöglicht die Lektüre von Bakhtins Texten im Licht der Psychoanalyse neue Interpretationen des Bewusstseinsbegriffs, die über die Grammatik des Subjekts, die Kontrolle und den Rationalismus hinausgehen. Obwohl es einerseits problematisch ist, eine „Konfluenz" zwischen Bakhtin und Lacan aufzuzeigen, sind es andererseits ihre Unterschiede, die neue Metaphern zwischen den beiden diskutierten Ansätzen verdeutlichen und erzeugen können.

Schlüsselwörter: Bakhtin, Lacan, Singularität, Sprache, Alterität 
Citação/Citation: Pinheiro, M. A., Aguiar, M. B., \& Carvalho, G. M. M. (2019, junho). Limites e possibilidades de interlocução entre o dialoguismo bakhtiniano e a psicanálise. Revista Latinoamericana de Psicopatologia Fundamental, 22(2), 254-277. http://dx.doi. org/10.1590/1415-4714.2019v22n2p254-6.

Editoras/Editors: Profa. Dra. Ana Maria G. R. Oda e Profa. Dra. Sonia Leite.

Submetido/Submitted: 12.7.2018 / 7.12.2018 Aceito/Accepted: 4.2.2019/2.4.2019

Copyright: (C) 2009 Associação Universitária de Pesquisa em Psicopatologia Fundamental/ University Association for Research in Fundamental Psychopathology. Este é um artigo de livre acesso, que permite uso irrestrito, distribuição e reprodução em qualquer meio, desde que o autor e a fonte sejam citados / This is an open-access article, which permits unrestricted use, distribution, and reproduction in any medium, provided the original authors and sources are credited.

Financiamento/Funding: Este trabalho não recebeu apoio / This work received no funding.

Conflito de interesses/Conflict of interest: As autoras declaram que não há conflito de interesses / The authors declare that there is no conflict of interest.

\section{Marina Assis Pinheiro}

Doutora em Psicologia Cognitiva pela Universidade Federal de Pernambuco - UFPE (Recife, PE, Br); Professora adjunta do Departamento de Psicologia da mesma universidade,

Avenida Professor Moraes Rego, 1235, Centro de Filosofia e Ciências Humanas

$9^{\circ}$ Andar - Cidade Universitária

50670-420 Recife, PE, Br

https://orcid.org/0000-0002-4019-0502

marinaassis.pinheiro@gmail.com

Mariana Bentzen Aguiar

Mestranda em Psicologia Cognitiva na Universidade Federal de Pernambuco - UFPE (Recife, PE, Br); Professora adjunta do Departamento de Psicologia da mesma universidade.

Avenida Professor Moraes Rego, 1235, Centro de Filosofia e Ciências Humanas

$9^{\circ}$ Andar - Cidade Universitária

50670-420 Recife, PE, Br

https://orcid.org/0000-0003-1402-9907

marianabentzen@gmail.com 


\section{ARTIGOS}

\section{Glória Maria Monteiro de Carvalho}

Professora da Pós-Graduação em Ciências da Linguagem na Universidade Católica de Pernambuco - UNICAP (Recife, PE, Br).

Rua Almeida Cunha, 245, Bloco G4, 8o Andar, Setor A - Boa Vista

50050-480 Recife-PE, Br

http://orcid.org.0000-0003-0595-1764

gmmcarvalho@uol.com.br

\section{ERRATA}

No artigo "Limites e possibilidades de interlocução entre o dialogismo bakhtiniano e a psicanálise" dos autores Marina Assis Ribeiro, Mariana Bentzen Aguiar, Glória Maria Monteiro de Carvalho, com número de DOI 10.1590/1415-4714.2019v22n2p254.6, publicado na Revista

Latinoamericana de Psicopatologia Fundamental, volume 22, número

2 (Rev.Latinoam.Psicopatol.Fundam. 22(2), 254-277, nas páginas 254 e 276

Onde se lia:

Marina Assis Ribeiro, Mariana Bentzen Aguiar, Glória Maria Monteiro de Carvalho

Leia-se

Marina Assis Pinheiro, Mariana Bentzen Aguiar, Glória Maria

Monteiro de Carvalho

This is an open-access article, which permits unrestricted use, distribution, BY-NC and reproduction in any medium for non-commercial purposes provided the original authors and sources are credited. 